\title{
$\beta$-HCG Level as a Predictive Marker of Pregnancy Progression or Retrogression
}

\author{
George Gborienemi Simeon ${ }^{1}$, Marymar Ezejimofor ${ }^{2}$, Newton Cleston Odumoson ${ }^{3}$ \\ ${ }^{1}$ Department of Medical Laboratory Science, Niger Delta University, Wilberforce Island, Yenagoa, Bayelsa State, Nigeria \\ ${ }^{2}$ Department of Medical Laboratory Science, College of Health Science, Nnamdi Azikiwe University, Awka, Nigeria \\ ${ }^{3}$ Department of Medical Laboratory Science, College of Health Science, Niger Delta University, Yenagoa, Bayelsa State, Nigeria \\ Email: *ozunugborie@gmail.com, Gentlemary@gmail.com,newtonsnn@gmail.com
}

How to cite this paper: Simeon, G.G. Ezejimofor, M. and Odumoson, N.C. (2021) $\beta$-HCG Level as a Predictive Marker of Pregnancy Progression or Retrogression. Open Journal of Obstetrics and Gynecology, 11, 713-719.

https://doi.org/10.4236/ojog.2021.116066

Received: March 6, 2021

Accepted: June 12, 2021

Published: June 15, 2021

Copyright (c) 2021 by author(s) and Scientific Research Publishing Inc. This work is licensed under the Creative Commons Attribution International License (CC BY 4.0).

http://creativecommons.org/licenses/by/4.0/

Open Access

\begin{abstract}
An ordered sequence of biologic events is precursors of the birth of a healthy baby. Hormonal interactions acting as a nexus between the fetus, placenta and mother that controls the establishment and progression of pregnancy and fetal development are very important. We examined the role of Beta-Human Chorionic Gonadotropin ( $\beta$-HCG) as a predictive marker. Applying radioimmunoassay that utilizes anti-sera generated from specific $\beta$-submit of HCG we evaluated the serum $\beta$-HCG level in 60 pregnant women in the three trimesters. Results showed that there was consistent increase in concentration that drops gradually and maintained a plateau only to drop from the $40^{\text {th }}$ week of pregnancy. 3 subjects (5\%) that had a sudden sharp drop in $\beta$-HCG level resulted in complications. Inclusion of $\beta$-HCG level screening and monitoring in pregnancy will raise assurance of progress or retrogression in pregnancy. We provide data that can be used as a reference range for $\beta$-HCG using this method.
\end{abstract}

\section{Keywords}

$\beta$-HCG, Predictive, Marker, Pregnancy, Progression, Retrogression

\section{Introduction}

There is agreement that the fetus, placenta and mother starts and sustain communication by means of the endocrine system once pregnancy has taken place. The endocrine milieu of human pregnancy is to a large extent controlled by placental hormones whose main function radiates around the modification of maternal physiology to enhance both the nutritional and physical requirements of the growing fetus. 
A review is desirable here of the pituitary-like hormone with Beta-human chorionic gonadotropin ( $\beta$-HCG) which is known to modulate endometrial growth and function. It has been proved in some earlier studies that where the level of HCG is not normal, the likelihood of the possibility of fetal growth restriction, and such other associated adverse pregnancy outcomes like preterm delivery and preeclamasia may occur [1] [2]. A glycoprotein that is biologically and immunologically similar to Leutenizing hormone, Human chorionic gonadotropin (HCG) is known to have a molecular weight of 36-to-40 KDa. Also similar to Follicle stimulating hormone (FSH), it is a heterodimer which is composed of an alpha $(\alpha)$ and Beta $(\beta)$ subunits. The $\alpha$ subunits of HCG, LH and FSH exhibit marked identity but the $\beta$ subunit differs [3] [4]. This difference confers specificity to each hormone. Being a Potent Luteopin, HCG enhances the stimulation of progesterone secretion by the corpus luteum. HCG enhances and prolongs the function of Corpus Luteum and converts the Corpus Luteum of the menstrual cycle into the corpus luteum of pregnancy. The production of progesterone is ensured in this cascade which is necessary for the establishment of Pregnancy. Viewed from the concept of selection, we can understand why pregnancy will ensure or not if the embryo is defective and cannot take control of the Corpus luteum. The ability of the embryo to produce adequate amount of HCG may be a pointer to a selection test of the embryo's endocrine competence. Moreover the maternal level of resistance to the embryo's effort to control corpus Leuteum would select embryos with more robust endocrine function [5] [6].

Chorionic gonadotropin mediates maternal recognition of pregnancy and its level is known to rise rapid in early pregnancy [7] and as further shown in [8] [9] as a major requirement for the growth of the embryo. Studies have also shown that HCG raises thyroid activity while at the same time influencing development and function of fetal activity and relaxation of uterine muscle. HCG affects the endometrial physiology even before its detection in the female blood circulation. There are a plethora of literature on previous studies that identifies the fact that chorionic gonadotropin produced by the blastocyst prolongs the window of implantation by inhibiting endometrial insulin-like growth factor binding protein (IGFBP-1) production, augmenting angiogenesis at the implantation site by increasing VEGE expression, modulating local cytokine and chemokine expression and augmenting local protease activity [10] [11].

It has also been documented that the placenta may not be the only source of HCG. The fetal kidney and fetal pituitary gland synthesize and secrete biologically active HCG [12]. This may explain why finding HCG in some adult nontrophoblastic tumor represents an atavistic reversion to a fetal form of hormone synthesis.

In normal pregnancies, HCG is detected 9 to 11 days after the mid cycle LH peak which is around 8 days after ovulation and only 1 day after implantation [13] [14] [15].

This makes it possible for pregnancy to be detected before the first missed 
menstrual period. This has utility when it becomes necessary for the determination of pregnancy of an early stage.

In this study we determined the B-HCG levels in 3 trimesters of subjects.

\section{Materials and Methods}

All subjects for this research work were females who were in early stage of Pregnancy. Confirmation was based on last menstrual flow data seen and subjects were recruited and tested for pregnancy using serum sample. Only those who show positive result were recruited. Patients were recruited from two tertiary hospitals, Diete Koki Memorial Hospital and Niger Delta University Teaching Hospital, Yenagoa, Bayelsa State, Nigeria, in March 2020 after obtaining their consent. Minimum sample size was calculated based on population.

Radioimmunoassay method was used in detecting - $\beta$-HCG level in the serum. In the reaction a limited amount of specific antibody $(\mathrm{AB})$ is reacted with corresponding hormone $\left({ }^{*} \mathrm{H}\right)$ labelled with a radioisotope. Upon addition of an increasing amount of the hormone $(\mathrm{H})$, a correspondingly increasing fraction of ${ }^{*} \mathrm{H}$ added is bound to the antibody. After separation of the bound from free ${ }^{*} \mathrm{H}$ by various means the amount of activity in the bound fractions was evaluated.

A microplate immunoenzymometric assay was used with, Accu Bind Elisa microwells (Product of Monobind Inc, Lake forest, C A 92630, USA). The reagents for this method include high affinity and specificity antibodies. The procedure relies on the fact that immobilization takes place at the surface of the microplate due to the reaction of the streptavidin. Several other reagents such as HCG streptavidin coated plates which consist of 96 wells were used along with wash solution. A microplate reader at wavelength of $450 \mathrm{~nm}$ and $620 \mathrm{~nm}$ wavelength was used for the absorbance measurement.

\section{Result}

Our evaluation excluded all those who had $\beta$-HCG level of $<0.5 \mathrm{miu} / \mathrm{ml}$. Those who had $\beta$-HCG above $20 \mathrm{miu} / \mathrm{ml}$ were considered positive and included in this research. Our findings are as shown in the Table $1 \&$ Table 2 and Figure 1.

Table 1. Concentration of B-HCG according to weeks of last menstrual period.

\begin{tabular}{ccc}
\hline \multicolumn{3}{c}{$\beta$-HCG concentration } \\
\hline Weeks & Lower limit & Highest limit \\
\hline $1-4$ & 5.0 & 440 \\
$5-8$ & 48 & 215,000 \\
$9-12$ & 18,500 & 335,000 \\
$13-16$ & 16,324 & 300,050 \\
$17-20$ & 16,240 & 244,000 \\
$21-24$ & 16,050 & 219,040 \\
\hline
\end{tabular}


Continued

\begin{tabular}{ccc}
\hline $25-28$ & 13,400 & 200,010 \\
$29-32$ & 12,105 & 177,210 \\
$33-36$ & 5250 & 153,004 \\
$37-40$ & 3250 & 103,111 \\
\hline
\end{tabular}

Table 2. Descriptive statistics.

\begin{tabular}{ccccccc}
\hline & $\mathrm{N}$ & Minimum & Maximum & \multicolumn{2}{c}{ Mean } & Std. Deviation \\
\cline { 2 - 7 } & Statistic & Statistic & Statistic & Statistic & Std. Error & Statistic \\
\hline LOWER LIMIT & 60 & 5.00 & $18,500.00$ & $10,117.2000$ & 2286.92922 & 7231.90517 \\
WEEKS & 60 & 1.00 & 10.00 & 5.5000 & 0.95743 & 3.02765 \\
HIGHER LIMIT & 60 & 440.00 & $300,050.00$ & $164,536.5000$ & $29,743.13290$ & $94,056.04471$
\end{tabular}

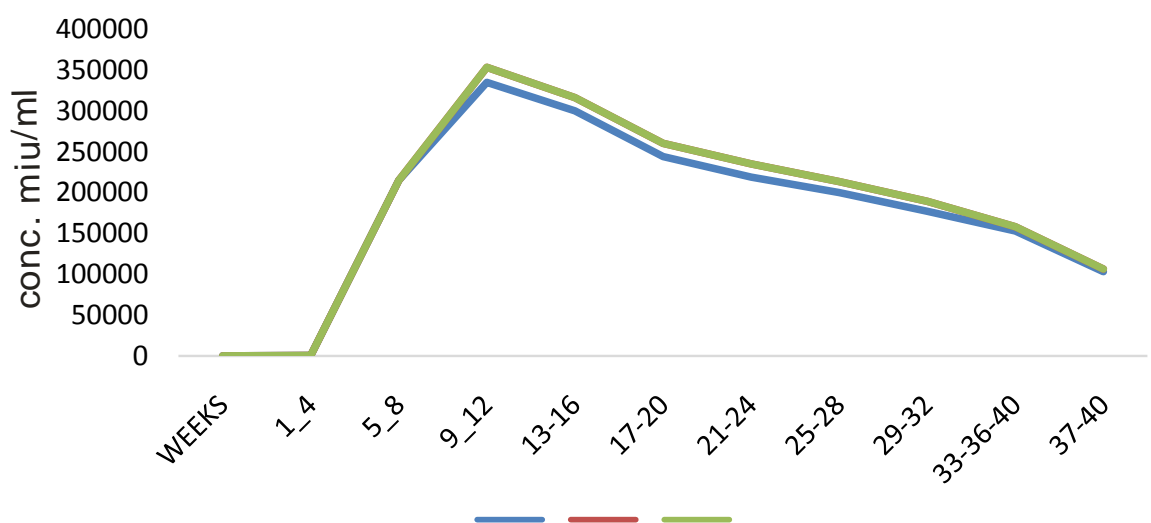

Figure 1. Graph showing the changes in hcg concentration in weeks.

We used SPSS version 23 for the statistical analysis. Descriptive statistics showed that the mean $\pm \mathrm{SD}$ for the upper and lower limit of $\beta$-HCG concentration are $164,536.5000 \pm 94,056.04471$ and 10,117.2000 \pm 7231.90517 respectively.

There was marked variation in the range of values for the lower and higher limit among the pregnant women. This shows that even within the range of weeks a significant difference exists with regards to the rate of production of HCG. Weeks 1 - 12 depicts rising HCG level of first trimester. The HCG value however shows moderate stability between weeks $13-24$, followed by a gradual reduction in level.

\section{Discussion}

In this study we examined the physiological role of pituitary-like hormone and evaluated the vital role played by human chorionic gonadotropin to modulate the endometrial growth and function during menstrual cycle.

Result obtained affirms the fact that marked variation exists among women in $\beta$-HCG production and is also time dependent. We observed a linear rise of HCG in pregnancy that reaches a peak, and then followed by a plateau phase 
which was observed to taper off in a decline phase. The least level was observed between the $1^{\text {st }}$ to $4^{\text {th }}$ weeks of pregnancy with a range of $5.0-440.3 \mathrm{miu} / \mathrm{ml}$ HCG among the pregnant women investigated. The plateau level was observed between weeks 13 - 25 which had HCG values ranging from 16,324 - 300,000 $\mathrm{miu} / \mathrm{ml}$ (see Table 1 and Figure 1).

The difference in range of HCG may explain the different pregnancy characteristics that may influence the concentration of HCG. HCG is known classically for maintenance of the corpus luteum and its progesterone production which is essential for embryo implantation [16] [17]. HCG is also known to play myriads of function. It has been shown by [18] that a nexus exist that links HCG with umbilical cord development, suppression of myometrial concentration, angiogenesis, regulation of immune tolerance and the promotion of growth and differentiation of fetal organs.

Above all, the main clinical utility of HCG level is within the domain of early pregnancy. Our findings epitomizes the fact that HCG is a precursor important molecule playing critical roles before, during and after pregnancy and also goes to suggest that variations in its level may be associated within adverse clinical outcomes. Indeed, this assertion has been shown by [19] [20] wherein fetal loss, preterm delivery and growth restriction were observed. The study of clinical association with HCG has become essential especially when considered that it could be used as a marker of gestational age. Moreover, HCG serves as a possible determinant when considering confounding and mediating reasons as it has to do with various measurement methodologies, population characteristics and dating strategies [21] [22].

The importance of the factors mentioned above has been clearly elucidated when we consider the fact that some maternal or fetal characteristics including smoking, placental weight, body-mass index (BMI), Parity, ethnicity and even gender are associated with an increased risk of adverse pregnancy outcome [23] [24].

\section{Conclusion}

The values obtained in our data could provide an insight as to the reasons for variation in $\beta$-HCG levels that could be used to offer explanation when complications are being studied in pregnancy and as reference value estimation of $\beta$-HCG in determination of pregnancy.

\section{Conflicts of Interest}

The authors declare no conflicts of interest regarding the publication of this paper.

\section{References}

[1] Abache, H. and Evel, A. (2006) Endometrial Receptivity Markers, the Journey to Successful Embryo Implantation. Human Reproduction Update, 12, 731-746. https://doi.org/10.1093/humupd/dml004 
[2] Diedrich, K., Fauser, B.C. and Devroey P. (2007) The Role of the Endometrium and embryo in Human Implantation. Human Reproduction Update, 13, 365-377. https://doi.org/10.1093/humupd/dmm011

[3] Haig, D. (1993) Genetic Conflicts in Human Pregnancy. Quarterly Review of Biology, 68, 495-532. https://doi.org/10.1086/418300

[4] Ball, S., Ekelund, C., Wright, D., Kirkegaard, I., Nørgaard, P., Petersen, O.B., et al. (2013) Temporal Effects of Maternal and Pregnancy Characteristics on Serum Pregnancy-Associated Plasma Protein-A and Free Beta-Human Chorionic Gonadotropin at 7-14 Weeks Gestation. Ultrasound in Obstetrics \& Gynecology, 41, 33-39. https://doi.org/10.1002/uog.11209

[5] Kliman, H.J. (2001) Uteroplacental Blood Flow: The Story of Decidualization, Menstruation, and Trophoblast Invasion. American Journal of Pathology, 157, 17591768. https://doi.org/10.1016/S0002-9440(10)64813-4

[6] Leng, T.Y., Chan, L.W., Leumg, T.N., Fung, T.Y., Sahotaa, D.S. and Lau, T.K. (2006) First Trimester Maternal Serum Levels of Placental Hormones Are Independent Predictors of Second Trimester Fetal Growth Parameters. Ultrasound in Obstetrics \& Gynecology, 27, 156-161. https://doi.org/10.1002/uog.2656

[7] Tanaka, M., Natori, M., Kolino, H., Ishimoto, H., Kobayashi, T. and Nozawas, S. (1993) Fetal Growth in Patients with Elevated Maternal Serum HCG Levels. Obstetrics \& Gynecology, 81, 341-343.

[8] Larsen, J., Buchanan, P., Johnson, S., Godbert, S. and Zinaman, M. (2013) Human Chorionic Gonadotropin as a Measure of Pregnancy Duration. International Journal of Gynecology \& Obstetrics, 123, 189-195. https://doi.org/10.1016/j.ijgo.2013.05.028

[9] Roland, M.C., Friis, C.M., Godang, K., Ballerster, J., Henriksen, T. and Haugen, G. (2014) Maternal Factors Associated with Fetal Growth and Birthweight Are Independent Determinants of Placental Weight and Exhibit Differential Effects by Fetal Sex. PLoS ONE, 9, e87303. https://doi.org/10.1371/journal.pone.0087303

[10] Kirkegaal, I., Ulaberg, N., Petersen, O.B., Torring, N. and Henriksen, T.B. (2010) PAPP-A Free Beta-HCG, and Early Fetal Growth Identify Two Pathways Leading to Pretern Delivery. Prenatal Diagnosis, 30, 956-963. https://doi.org/10.1002/pd.2593

[11] Cole, L.A. (2010) Biological Functions of HCG and HCG Related Molecules. Reproductive Biology and Endocrinology, 8, Article No. 102. https://doi.org/10.1186/1477-7827-8-102

[12] Reisinger, K., Ball, N., Me Kinnon, T., Munstedt, K. and Zygmumt, M. (2007) The Gonadotropins: Tissue-Specific Angiogenic Factors. Molecular and Cellular Endocrinology, 269, 65-80. https://doi.org/10.1016/j.mce.2006.11.015

[13] Bock, J.L. (1990) HCG Assays: A Plea for Uniformity. American Journal of Clinical Pathology, 93, 432-433. https://doi.org/10.1093/ajcp/93.3.432

[14] Cole, L.A., Shahabi, M.S. and Butter, S.A. (2001) Utility of Commonly Used Commercial Human Chorionic Gonadotropin Immunoassays in the Diagnosis and Management of Trophoblastic Diseases. Clinical Chemistry, 47, 308-315. https://doi.org/10.1093/clinchem/47.2.308

[15] Jakowiuk, A., Filipiak, P., Bartak, J., Pienkos, P. and Kowalska, E. (2012) Laboratory Automatic Measurement System for Gamma Specimen. Nucleonika, 57, 633-635.

[16] Reis, F.M. and Petragla, F. (2001) The Placenta as a Neuroendocrine Gland. Frontiers of Hormone Research, 27, 216-218. https://doi.org/10.1159/000061028 
[17] Leton, E.A., Neal, L.M. and Sulaimah, R. (1982) Plasma Concentrations of Human Chorionic. Gonadotropin from the Time of Implantation until Second Week of Pregnancy. Fertility and Sterility, 37, 773-778. https://doi.org/10.1016/S0015-0282(16)46337-5

[18] Zinaman, M., Johson, S., Ellis, J. and Ledger, W. (2012) Accuracy of Perception of Ovulation Day in Women Trying to Conceive. Current Medical Research and Opinion, 28, 749-754. https://doi.org/10.1185/03007995.2012.681638

[19] Mook-Kanamori, D.O., Steegers, E.A.P., Filers, P.H., Raat, H., Hofman, A. and Jaddoe, V.W.V. (2010) Risk Factors and Outcomes Associated as with First-Trimester Fetal Growth Restriction. JAMA, 303, 527-534.

https://doi.org/10.1001/jama.2010.78

[20] Goetzl Krantz, D. and Simpson, J.L. (2004) Pregnancy Associated Plasma Protein A, Free Beta-HCG, Nuchal Translucency and Risk of Pregnancy Loss. Obstetrics \& Gynecology, 104, 30-36. https://doi.org/10.1097/01.AOG.0000129969.78308.4f

[21] Strott, C.A., Yoshimi, T., Ross, G.T. and Lipset, M.B. (1969) Ovarian Physiology; Relationship between Plasma LH and Steroidogenesis by the Follicle and Corpus Luteum; Effect of HCG. The Journal of Clinical Endocrinology \& Metabolism, 29, 1157-1167. https://doi.org/10.1210/jcem-29-9-1157

[22] Keikkala, E., Vuorela, P., Laivuori, H., Romppanen, J., Heinonen, S. and Stenman, U.-H. (2013) First Semester Hyperglycosylated Human Chorionic Gonadotropin in serum-A Marker of Early Onset of Preeclampsia. Placenta, 34, 1059-1065. https://doi.org/10.1016/j.placenta.2013.08.006

[23] Vogt Isaksen, C., Austgulen, R., Chedwick, L., Romundstad, P., Vatten, L. and Craven, C. (2004) Maternal Smoking, Growth Restriction, and Placental Apoptosis. Pediatric and Developmental Pathology, 7, 433-442. https://doi.org/10.1007\%2Fs10024-004-0105-1

[24] Olsen, R.N., Weolkers, D., Dunsmoor-Su, R. and Lacoursiere, D.Y. (2012) Abnormal Second-Timester Serum Analytes Are More Predictive of Preterm Preeclampsial. American Journal of Obstetrics \& Gynecology, 207, 228.E1-228.E7. https://doi.org/10.1016/j.ajog.2012.06.006 